\title{
COMPETÊNCIAS COLETIVAS E DESEMPENHO COLETIVO: UM ESTUDO COM EQUIPES DE GASTRONOMIA
}

\section{COLLECTIVE COMPETENCIES AND COLLECTIVE PERFORMANCE: A STUDY OF GASTRONOMY TEAMS COMPETENCIAS COLECTIVAS Y DESEMPEÑO COLECTIVO: UN ESTUDIO CON EQUIPOS DE GASTRONOMÍA}

\author{
CLÁUDIA CINTRA BORTOLETTO GIANSANTE \\ Doutoranda \\ Universidade de Guarulhos - Brasil \\ claudiagiansante@gmail.com \\ LUCIANO VENELLI-COSTA \\ Doutor \\ Universidade Metodista de São Paulo - Brasil \\ luciano.costa@metodista.br
}

ALMIR MARTINS VIEIRA

Doutor

Universidade Metodista de São Paulo - Brasil almir.vieira@gmail.com

JOEL SOUZA DUTRA

Doutor

Universidade de São Paulo - Brasil jdutra@usp.br

Submetido em: 09/12/2014 Aprovado em: 16/12/2015

Doi: alcance.v22n4.p457-472

\section{RESUMO}

Este trabalho tem por objetivo principal analisar a influência das competências coletivas sobre o desempenho coletivo de equipes de alunos de gastronomia de uma universidade privada. Com uma proposta metodológica quali-quantitativa, o estudo utilizou o método comparativo e a técnica de observação em 12 encontros para trabalhos coletivos no Laboratório de Alimentos, por 131 alunos distribuídos em 21 equipes: 10 equipes do quarto período e 11 do segundo período. As equipes foram observadas de forma sistemática, uma aula prática semanal, período de quatro meses sequenciais e avaliadas por meio de dois instrumentos de coleta de dados: 0 formulário quali-quantitativo de competência coletiva e o formulário de notas acadêmicas. Para análise dos dados, a pesquisa empregou métodos estatísticos para obter as médias dos escores quantitativos das variáveis para testes de correlação, cálculo do coeficiente de correlação de Pearson, além de interpretações qualitativas de indicadores de competências coletivas. A correlação positiva entre competências coletivas e desempenho coletivo apareceu apenas nas equipes do quarto período que já trabalham juntas há mais de um ano, e se diferenciaram pela presença de liderança e indicadores de competências coletivas.

Palavras-Chave: Competências Coletivas. Desempenho Coletivo. Equipes de Gastronomia.

\section{ABSTRACT}

This work analyzes the influence of collective competence on the collective performance of teams of gastronomy students at a private university. With a qualitative and quantitative methodology, the study uses the comparative 
method and the observation technique in twelve meetings of collective works in the Food Laboratory, by 131 students divided into twenty-one teams: ten teams in the fourth period and eleven in the second period. The teams were observed systematically, in weekly practical classes held over a four-month period, and evaluated using two data collection instruments: the qualitative/quantitative collective competence form, and the academic scores form. For the data analysis, the research used statistical methods to obtain the mean scores for the quantitative variables for use in correlation tests, calculating the Pearson correlation coefficient, and qualitative interpretations of collective competence indicators. The positive correlation between collective competences and collective performance appeared only for the teams in the fourth period, who had already been working together for over a year, and were differentiated by the presence of leadership and collective competence indicators.

Keywords: Collective Competences. Collective Perfomance. Gastronomy Teams.

\section{RESUMEN}

Este trabajo tiene por principal objetivo analizar la influencia de las competencias colectivas sobre el desempeño colectivo de equipos de alumnos de gastronomía de una universidad privada. Con una propuesta metodológica cualitativa y cuantitativa, el estudio utilizó el método comparativo y la técnica de observación en 12 encuentros para trabajos colectivos en el Laboratorio de Alimentos, con 131 alumnos distribuidos en 21 equipos: 10 equipos del cuarto semestre y 11 del segundo semestre. Los equipos fueron observados de forma sistemática en una clase práctica semanal, período de cuatro meses consecutivos y evaluados por medio de dos instrumentos de recolección de datos: el formulario cualitativo y cuantitativo de competencia colectiva y el formulario de notas académicas. Para el análisis de los datos la investigación empleó métodos estadísticos para obtener las medias de los escores cuantitativos de las variables para pruebas de correlación, cálculo del coeficiente de correlación de Pearson, además de interpretaciones cualitativas de indicadores de competencias colectivas. La correlación positiva entre competencias colectivas y desempeño colectivo apareció únicamente en los equipos del cuarto semestre que ya trabajaban juntos hacía más de un año, y se diferenciaron por la presencia de liderazgo e indicadores de competencias colectivas.

Palabras Clave: Competencias Colectivas. Desempeño Colectivo. Equipos de Gastronomía.

\section{INTRODUÇÃO}

A globalização e as inovações tecnológicas produziram mudanças na forma de organizar o trabalho e, nesse cenário, as equipes de trabalho ganharam espaço no processo produtivo e na tomada de decisões dos gestores. Usadas como vantagem competitiva, as equipes tornaram-se peças fundamentais no desempenho organizacional (PUENTE-PALÁCIOS; SEIDL; SILVA, 2007) por contribuírem com a qualidade e com a inovação de produtos (MACHADO, 1998), um fenômeno global cada vez mais empregado nas organizações.

Desde a década de 1960, as equipes de trabalho são formalmente estudadas (KATZENBACH, 2001), mas somente a partir dos anos 1990 passaram a ser utilizadas como estratégia de negócios no mercado competitivo. Entretanto, por muito tempo, as empresas valorizaram somente o trabalho individual. Formavam-se grupos que atuavam de forma isolada, com entrosamento superficial e com pouca disposição para o trabalho em conjunto (DUHÁ, 2007).

Gradativamente, empresas favoráveis ao desenvolvimento das equipes adotaram, além da forma individual de trabalho, o trabalho coletivo nos ambientes de trabalho. Representam um conjunto de indivíduos que produz o trabalho diferentemente do grupo. Para Katzenbach e Smith (1994), nas equipes a responsabilidade é individual e mútua ao mesmo tempo. Há sinergia e esforço entre os membros na busca de melhores resultados coletivos que, segundo Duhá (2007), são maiores que a simples soma dos desempenhos individuais. Nas equipes há um objetivo comum e claro, os membros usam suas habilidades individuais em prol dos resultados coletivos.

As práticas empresariais evidenciaram que as equipes trazem múltiplas competências individuais e coletivas, melhores resultados coletivos, ao aliarem a realização profissional dos membros a um objetivo comum: a meta (WEBER; GRISCI, 2010). Nas equipes consolidadas, os talentos individuais multiplicam-se para proporcionar melhor desempenho organizacional. Como unidades de desempenho produzem vantagens competitivas? Devido ao aumento da qualidade, da produtividade dos produtos, da rapidez de resposta e das 
mudanças tecnológicas (MOSCOVICl, 2010). Nesse sentido, a composição das equipes contribui para o aprimoramento da estrutura organizacional (KATZENBACH; SMITH, 1994) por meio do comprometimento dos membros com os resultados e solução dos problemas organizacionais (IVANCEVICH, 2008), surgindo, a partir da década de 70, investimentos no trabalho em equipe em função de seus benefícios e por serem, segundo Puente-Palácios e Souza (2009), já reconhecidas como unidades efetivas de desempenho organizacional.

0 presente estudo adota a perspectiva social das competências coletivas (CCs), focada no comportamento e nas relações dos indivíduos (atores sociais), relações interorganizacionais (WEICK, 1993; WEICK; ROBERTS, 1993; SANDBERG, 2000; FHOHM, 2002; HANSSON, 2003; LE BOTERF, 2003; BOREHAM, 2004; RETOUR; KROHMER, 2011) e das equipes. Segundo Le Boterf (2003), emerge uma competência coletiva (CC) formada a partir das relações sociais que o grupo estabelece. Nos contextos organizacionais (RETOUR; KROHMER, 2011), a CC surge das relações de cooperação e sinergia entre as competências individuais focadas na melhora do desempenho coletivo, um diferencial que os concorrentes têm dificuldade de copiar e, por isso, um desafio às empresas que buscam desempenho e competitividade.

Nesse sentido, a gestão das competências coletivas (CCs) melhora o desempenho das equipes e amplia as ações coletivas nas organizações. $O$ trabalho é executado de modo qualificado e focado em metas, deixa de ser tratado apenas do ponto das competências individuais, competências organizacionais, condições do contexto (RETOUR; KROHMER, 2011; ZAMPIER; TAKAHASHI, 2014). A partir dos anos 1990, os modelos de gestão de empresas passaram a valorizar as práticas coletivas (BONOTTO; BITENCOURT, 2006), e o conceito de CC ganhou destaque na gestão por competências.

Para Retour e Krohmer (2011), as CCs representam um elo-chave de conexão entre as competências individuais (Cls) e as competências organizacionais (COs). Para o estudo, o desenvolvimento das Cls ocorre nas interações com 0 ambiente de trabalho cujos profissionais mobilizam o capital social que dispõem e entregas em níveis de complexidade e de acordo com seus espaços ocupacionais nas empresas (DUTRA, 2004; FLEURY; FLEURY, 2013). Para Le Boterf (2003), o desenvolvimento das Cls requer também dos profissionais: saber aprender com as experiências; saber elaborar o que é compartilhado; saber comunicar-se, cooperar; e saber aprender de forma coletiva, conforme o contexto de trabalho. Para Weick e Roberts (1993), é um saber coletivo formado pelas experiências individuais, um espírito coletivo necessário a uma aprendizagem efetiva. Já as COs resultam das Cls presentes nas áreas de trabalho (FLEURY; FLEURY, 2004).

Nos contextos organizacionais, os profissionais assumem responsabilidades, buscam reconhecimento $e$ recompensas por suas habilidades e inteligência prática nas situações de trabalho (LE BOTERF, 2003; SANDERBERG, 2000; ZARIFIAN, 2001). A integração das Cls, CCs, COs facilita 0 acesso a uma rede de profissionais, transferência de conhecimento e criação e desenvolvimento das competências-chave: a vantagem competitiva (GRIAMAND, 2011 apud RETOUR; KROHMER, 2011) e, por isso, na gestão das CCs espera-se a melhora do desempenho coletivo (RETOUR; KROHMER, 2011). Desta forma, o desenvolvimento das CCs requer a formação de equipes, interações sociais e condições de trabalho favoráveis para um desempenho coletivo (DC) que possa atender às demandas organizacionais.

A questão investigativa deste estudo é: as competências coletivas em uma equipe de trabalho influenciam o desempenho coletivo?

$O$ contexto da pesquisa é uma universidade privada, junto a equipes de estudantes de um curso superior de Tecnologia em Gastronomia nas atividades práticas do Laboratório de Alimentos (LA). As equipes são observadas em doze trabalhos coletivos para a execução de receitas gastronômicas e, ao final de cada aula prática, um docente avalia a produção. Cada equipe recebe uma nota acadêmica.

0 objeto da pesquisa são as equipes de trabalho, conceituadas por Katzenbach (2001) como um pequeno número de pessoas com habilidades complementares entre si, comprometidas com metas de desempenho e objetivos comuns pelos quais se sentem mutuamente responsáveis para melhora no desempenho coletivo (RETOUR; KROHMER, 2011). O conceito de desempenho coletivo ainda é pouco presente na literatura científica de equipes e, no presente estudo, é empregado como similar ao conceito de desempenho de equipes.

O objetivo principal é analisar a influência das CCs sobre o desempenho de equipes de alunos de gastronomia de uma universidade privada e, como objetivos específicos, o estudo busca: i) analisar a correlação entre competências coletivas e desempenho coletivo; ii) identificar a emergência de competências coletivas durante as tarefas em equipe; e iii) comparar as características qualitativas da equipe com suas competências 
coletivas. A pesquisa realiza a coleta de dados quali-quantitativos de CCs e características das equipes e notas acadêmicas de desempenho coletivo para análise das equipes de gastronomia.

O artigo é constituído por quatro partes, além desta introdução. Na primeira, são apresentados os principais conceitos que versam sobre as CCs e DC. Na segunda, consta a postura metodológica assumida para consecução da pesquisa, seguida da terceira parte, na qual se discute a respeito dos dados obtidos em campo. A última parte traz as considerações finais, originadas a partir do desafio assumido, além de indicações para futuras pesquisas.

\section{REVISÃO TEÓRICA}

\section{Competências Coletivas (Cc)}

No campo das competências coletivas, Le Boterf (2003) considera que as CCs resultam das relações de cooperação e sinergia entre as competências individuais dos integrantes das equipes. Para Boreham (2004), representa a consciência que os membros da equipe têm sobre as atividades desenvolvidas na direção de um objetivo comum. Segundo Silva (2012), não existe ainda um consenso, o conceito de CCs encontra-se em fase de apropriação. Entretanto a autora destaca ser possivel encontrar nos autores elementos (indicadores) que auxiliam na identificação das CCs: interações afetivas, aprendizagem coletiva (LE BOTERF, 2003), sentido coletivo, base de conhecimento comum, senso de interdependência de tarefas (BOREHAM, 2004) e elementos da memória coletiva, referencial comum, linguagem compartilhada, engajamento subjetivo (RETOUR; KROHMER, 2011), conforme ilustrado no Quadro 1.

Para Retour e Krohmer (2011) e Le Boterf (2003), as CCs ocorrem no âmbito do grupo e o campo de conhecimento se desenvolve em duas perspectivas: uma vertente funcional, que considera a CC um conjunto de recursos produtivos, funcionais, que reforçam as competências organizacionais (COs) nos diferentes setores da empresa; e outra é perspectiva social, segundo a qual a CC é o comportamento fruto das relações entre conjuntos de indivíduos ou atores sociais e suas relações interorganizacionais. Nos estudos organizacionais, os pesquisadores focavam, inicialmente, a dimensão individual. Nos primeiros estudos de CC, as pesquisas de Weick (1993) e Weick e Roberts (1993) destacaram o conceito de compartilhamento do trabalho, um processo coletivo do grupo denominado sensemaking e que significa "dar sentido à ação". Uma habilidade em dar resposta a um evento específico e que emerge de um "espírito coletivo" (WEICK, 1993).

A presença de uma "mente coletiva" determina aos indivíduos e ao coletivo a criação de um padrão nas atividades interrelacionadas (WEICK; ROBERTS, 1993), uma reflexão intencional que forma as bases para a ação. Para Frohm (2002), uma lógica interativa que define os objetivos, a forma como será executado o trabalho, como cada membro contribuirá nas atividades por meio de uma lógica interativa sobre "o que fazer" e uma lógica interrelacional de "como fazer", presentes no ciclo de manutenção e desenvolvimento da CC.

Frohm (2002) e Hansson (2003) valorizam o contexto em que os atos da equipe são compartilhados para a formação de uma estrutura de imagem coletiva, constituída de pensamentos comuns usados para interpretar o contexto em prol de um objetivo comum. Estes dependem de uma habilidade presente no conjunto de indivíduos, composta por uma tríade de competências práticas, interpessoais e solidárias de interação entre colegas, dentro e fora do ambiente de trabalho (RUAS; ANTONELLO, 2005; BONOTTO; BITENCOURT, 2006). Para Le Boterf (2003), a competência emerge da cooperação e sinergia presentes nas competências individuais. Nos contextos organizacionais são competências originadas de um conjunto de relações mútuas e de cooperação entre profissionais, fontes de desempenho.

Quanto à formação, a CC apresenta conteúdos básicos que a identificam, tais como saber elaborar os saberes compartilhados, saber comunicar-se, saber cooperar e saber aprender coletivamente (LE BOTERF, 2003). Esse saber coletivo forma-se nas experiências individuais compartilhadas que consolida no grupo um espírito coletivo, uma aprendizagem efetiva (WEICK; ROBERTS, 1993), condicionada às variáveis do contexto de trabalho da equipe e da organização (LE BOTERF, 2003).

Como atributos da CC, Retour e Krohmer (2011) destacam quatro principais: o "referencial comum", que exige que os membros tenham referências conhecidas por todos; a "linguagem compartilhada", um vocabulário próprio utilizado para compartilhar informações, saberes entre todos os membros e usada para se comunicarem; a "memória coletiva", aprendizagens que os indivíduos adquirem na interação coletiva dos membros e que irá compor um repertório de conhecimentos coletivos da equipe; e o "engajamento subjetivo", envolvimento que cada membro tem pelo trabalho. Como fatores de criação e desenvolvimento: o "capital 
humano das competências individuais", o "potencial das competências individuais de cada membro do grupo"; as "interações afetivas", as "relações informais" e a "cooperação". Como fatores organizacionais: a "composição das equipes", as "interações formais", o "estilo de gestão" e os "pressupostos da gestão de recursos humanos". Concluem que a CC depende das Cls de cada indivíduo e da coletividade e compartilham com Le Boterf (2003) que as interações afetivas influenciam fortemente a CC, à medida que seus membros se sintam à vontade, tenham prazer em trabalhar juntos, valorizem a experiência em comum, formando uma imagem positiva da equipe.

A emergência da CC depende de condições do contexto favoráveis ao compartilhamento das Cls na direção do resultado esperado (ZARIFIAN, 2001). Na interação os indivíduos adquirem o sentido coletivo necessário à formação dos processos mentais coletivos (WEICK; ROBERTS, 1993) de criação da CC. Le Boterf (2003) destaca a cooperação entre competências individuais; linguagem comum; relações de ajuda e apoio mútuo; núcleo comum de competências para o trabalho; circulação dos indivíduos nas estruturas (papéis e projetos); diversidade de competências profissionais (procura e oferta); solidariedade; coesão afetiva e qualidade nas interações; ciclos de aprendizagem; memória organizacional; base coletiva de conhecimentos e práticas profissionais. Por fim, a integração de saberes e competências em um espaço de desenvolvimento e de tempo apropriados à emergência da CC nas equipes. Nesta cadeia produtiva, o coletivo ocorre em dois níveis: (1) visão intragrupo - interação dos membros de um grupo; e (2) visão intergrupos - interação de grupos de trabalho e processos de CC no nivel organizacional (BITENCOURT; KLEIN, 2009).

A CC traz benefícios aos indivíduos e às organizações ao promover estruturas de trabalho mais flexíveis e menos hierarquizadas. Os empregados têm maior grau de envolvimento e colaboração, autonomia para fazer a autogestão do trabalho, identificação com os produtos. Além disso, possuem sentido coletivo e senso de interdependência de tarefas voltados à criação de uma base de conhecimento comum e foco na melhoria contínua da organização e das equipes (BOREHAM, 2004). Nesse sentido, quanto maior a presença das $\mathrm{Cls}$, melhores serão as CCs compartilhadas, e as atitudes de cooperação voltadas aos objetivos comuns e ao surgimento de novas CCs (RETOUR; KROHMER, 2011). Entretanto Colin e Grasser (2011) acreditam que não basta apenas ver uma equipe em atividade prática. É preciso uma dinâmica de compartilhamento para transformação e criação de novas CCs.

O Quadro 1 sintetiza a proposição dos autores (e conceitos) adotados pelo estudo. Estes elementos de CCs foram utilizados na metodologia como indicadores do formulário de CCs. 
Quadro 1 - Autores e elementos das competências coletivas

\begin{tabular}{|c|c|c|}
\hline Autor & $\begin{array}{l}\text { Elementos de } \\
\text { Competência Coletiva }\end{array}$ & Descrição \\
\hline \multirow{2}{*}{$\begin{array}{l}\text { Le Boterf } \\
(2003)\end{array}$} & Aprendizagem Coletiva & $\begin{array}{l}\text { Intercâmbio de conhecimentos e experiências individuais voltado à } \\
\text { aprendizagem coletiva. }\end{array}$ \\
\hline & $\begin{array}{l}\text { Interações } \\
\text { Afetivas }\end{array}$ & $\begin{array}{l}\text { Interações afetivas que permitem aos membros se sentirem à vontade e terem } \\
\text { prazer no trabalho em conjunto. }\end{array}$ \\
\hline \multirow{3}{*}{$\begin{array}{l}\text { Boheram } \\
\text { (2004) }\end{array}$} & $\begin{array}{l}\text { Base de Conhecimento } \\
\text { Comum }\end{array}$ & $\begin{array}{l}\text { Criação de uma estrutura de conhecimento comum aos membros para que o } \\
\text { grupo disponha de uma referência conhecida. }\end{array}$ \\
\hline & $\begin{array}{l}\text { Senso de } \\
\text { Interdependência de } \\
\text { Tarefas }\end{array}$ & $\begin{array}{l}\text { Capacidade de perceber que o trabalho requer ações interdependentes dos } \\
\text { membros na realização das tarefas. }\end{array}$ \\
\hline & Sentido Coletivo & Ações individuais voltadas ao coletivo. \\
\hline \multirow{5}{*}{$\begin{array}{l}\text { Retour e } \\
\text { Krohmer } \\
(2011)\end{array}$} & $\begin{array}{l}\text { Capital } \\
\text { Humano }\end{array}$ & $\begin{array}{l}\text { Competências individuais que caracterizam o capital humano da equipe para } \\
\text { realização de tarefas. }\end{array}$ \\
\hline & $\begin{array}{l}\text { Cooperação } \\
\text { Compartilhada }\end{array}$ & $\begin{array}{l}\text { Troca compartilhada entre os integrantes focada na aprendizagem e na } \\
\text { realização de projetos em comum. }\end{array}$ \\
\hline & Engajamento Subjetivo & Coletivo de indivíduos engajado no exercício do trabalho. \\
\hline & $\begin{array}{l}\text { Linguagem } \\
\text { Compartilhada }\end{array}$ & $\begin{array}{l}\text { Informações compartilhadas entre os membros com vocabulário que a equipe } \\
\text { dispõe para conversar. }\end{array}$ \\
\hline & Memória Coletiva & $\begin{array}{l}\text { Criação de um novo saber pela interação e confronto de saber-fazer de dois ou } \\
\text { mais indivíduos no trabalho em conjunto. }\end{array}$ \\
\hline
\end{tabular}

Fonte: Adaptado de Le Boterf (2003), Boreham (2004) e Retour e Krohmer (2011).

\section{Desempenho Coletivo (DC)}

Mudanças nos processos organizacionais promoveram a adoção do conceito de equipes como unidades de desempenho (PUENTE-PALÁCIOS; BORGES-ANDRADE, 2005). Graças à evolução tecnológica e às ferramentas estatísticas, estudos das variáveis preditoras de desempenho foram realizados visando à promoção do sucesso organizacional (BEDANI, 2007; MICHAUX, 2011). Araujo e Cançado (2011) definem desempenho como 0 alcance de metas e resultados tangíveis obtidos por equipes. Segundo Vasquez et al. (2013), elas constituem uma variável associada aos conceitos de eficiência, competência, produtividade e, por isso, muito utilizadas na gestão de desempenho nas organizações.

$\mathrm{Na}$ análise do desempenho de equipes, Katzenbach e Smith (1994) propõem o modelo "curva de desempenho", composto por estágios de formação e níveis de desempenho das equipes nas atividades. No primeiro estágio, "Grupo de Trabalho", a equipe compartilha as informações do trabalho sem um propósito comum. No estágio seguinte, a "Pseudoequipe" é uma equipe ainda sem propósitos e metas de desempenho comuns. Na sequência vem a "Equipe Potencial", na qual não há ainda responsabilidade e senso coletivo estabelecido. Só no quarto estágio, "Equipe Real", é que ocorre maior incremento no desempenho. E no último estágio, "Equipe de Alto Desempenho", há membros comprometidos com crescimento e sucesso dos colegas e chega-se ao ápice da curva, formando-se uma equipe real com melhores desempenhos. É eficaz e constituída por integrantes participativos, interessados nas tarefas, receptivos às novas ideias e às soluções consensuais de conflitos (KATZENBACH; SMITH, 1994; BENDERS; VAN HOOTEGEM, 1999).

As equipes eficazes possuem propósitos claros, os membros agem informalmente e com participação de todos (PARKER, 1994); escutam com atenção e as divergências são resolvidas com decisões consensuais e de modo civilizado. Desenvolvem uma comunicação aberta, seus integrantes têm papéis bem definidos, liderança compartilhada, aceitação à diversidade no grupo e nas relações externas, além da realização de autoavaliação periódica de atuação e eficácia. 
Pesquisas sobre 0 conceito de interdependência de tarefas e resultados mostram que o desempenho coletivo depende da cooperação dos membros para a correta realização do trabalho e para ter maior probabilidade de atingir bons resultados (PUENTE-PALACIOS, 2008).

Para os autores Blanchard et al. (2007), melhores resultados dependem da aprendizagem que se constrói nas equipes, o que requer um ambiente de confiança e de compartilhamento de informações entre os integrantes para compromissos coletivos. Nas equipes de excelência, é um pensar em conjunto e na direção de desempenhos coletivos.

A revisão da literatura apresentada evidencia que os pesquisadores de $D C$ não especificam formas de como é possível avaliar o desempenho ou diferenciá-lo do desempenho individual. Eles apenas referem-se às equipes e aos seus estágios de desempenho, reforçando características que já são discutidas como competências coletivas de uma equipe de alto desempenho.

Reconhece-se, portanto, que uma equipe de alto desempenho tem forte propósito e valores compartilhados, os membros confiam na habilidade da equipe em superar os obstáculos (MICHAUX, 2005); a comunicação é aberta, posto que os membros compreendem que todos são responsáveis pelo desempenho e pelo desenvolvimento e exercem liderança compartilhada na equipe para gerar altos níveis de produtividade.

0 próximo tópico apresenta os procedimentos metodológicos adotados na pesquisa: métodos e técnicas aplicados, além dos instrumentos de coleta de dados que permitiram a avaliação das equipes de gastronomia.

\section{PROCEDIMENTOS METODOLÓGICOS}

Este estudo se configura como uma pesquisa descritiva que avalia a influência das CCs (competências coletivas) sobre os DCs (desempenhos coletivos). Segundo Rodrigues (2006), a pesquisa descritiva analisa as relações entre variáveis de um determinado objeto de estudo, sem manipulação das variáveis; e identifica e avalia as relações entre as variáveis à medida que estas se manifestam, espontaneamente, no contexto da pesquisa.

O contexto da pesquisa é uma universidade privada localizada na Grande São Paulo, especificamente, seu curso superior de Tecnologia em Gastronomia (CSTG), composto de quatro períodos teórico-práticos e semestrais que tratam de temas das diversas culturas alimentares presentes na formação do profissional de gastronomia. A cada aula prática, que acontece no segundo e quarto períodos do curso, um docente apresenta um tema da gastronomia e as técnicas de preparo de receitas. Em seguida, as equipes ocupam as bancadas de trabalho no Laboratório de Alimentos (LA), nas quais os alunos têm à disposição equipamentos e utensílios de cozinha utilizados no preparo de pratos da cozinha brasileira, cozinha fria, confeitaria e panificação.

A amostra envolveu 131 estudantes do curso. Destes, 65 alunos formavam as dez equipes do quarto período e 66 alunos formavam as 11 equipes do segundo período. Equipes com composição de quatro a sete integrantes. $O$ segundo período compreende alunos que estão em sua primeira experiência no $L A$, e que se conhecem no curso há menos que um ano. $O$ quarto período compreende equipes que já se conhecem há pelo menos um ano e meio e que já trabalharam juntas no LA desde o segundo período.

O estudo teve início no segundo semestre de 2012, em seis de agosto, primeiro dia de aula, quando os próprios alunos formaram suas equipes por um critério de afinidade. Foi realizado um seminário sobre equipes de trabalho e apresentação da pesquisa e seus objetivos. Obteve-se aceite geral das 21 equipes. A partir do segundo dia de aula, iniciaram-se as observações. A etapa de coleta de dados encerrou-se no dia seis de novembro de 2012, quando se iniciou a etapa de análise e discussão dos resultados.

Pautado pelo método comparativo e por uma abordagem quali-quantitativa, o estudo avaliou dez indicadores quantitativos e quatro indicadores qualitativos de CCs, além de doze notas acadêmicas das equipes por turma. Utilizou métodos estatísticos para obter as médias dos escores dos indicadores quantitativos de CCs e DCs, escalonados em escala Likert de 1 a 5 , e que foram usadas para os testes de correlação das variáveis e cálculo do coeficiente de correlação de Pearson.

Foi utilizada a técnica de observação para apontamentos dos dados dos indicadores quali-quantitativos de competências coletivas e características das equipes; e notas acadêmicas como indicador de Desempenho Coletivo, com registro nos respectivos formulários da pesquisa. A técnica de observação, segundo Rodrigues (2006), possibilita a coleta de dados a partir da observação e do registro de forma direta do fenômeno em 
análise. Optou-se pela observação não participante por serem 21 equipes e volume de dados quali-quantitativos coletados por uma única pesquisadora. As 12 observações aconteceram de modo sistemático no período de quatro meses sequenciais (6/8 a 6/11/2012) nas aulas práticas semanais no LA por turma (segundo e quartoperíodos). Segundo Le Boterf (2003), justifica-se a abrangência das 12 observações "em campo" em virtude de que o tempo (doze observações semanais) e o espaço (aulas no Laboratório de Alimentos) são requisitos necessários à emergência das CCs no trabalho em equipe.

$\mathrm{Na}$ etapa de coleta de dados foram empregados dois instrumentos: Formulários de Competências Coletivas e Notas Acadêmicas. A cada observação das equipes no LA foram preenchidos formulários para as turmas do segundo e quarto períodos. Para análise dos dados utilizaram-se métodos estatísticos para obter as médias das variáveis de CCs e DCs usadas para os testes de correlação, cálculo do coeficiente de correlação de Pearson, além de interpretações qualitativas dos dados de CCs. Os dados quantitativos foram tratados com o uso do Software estatístico SPSS-Statistical Package for the Social Science, versão 18.0

A seguir, as etapas, materiais e métodos empregados no estudo (Quadro 2).

Quadro 2 - Pesquisa: etapas, materiais e métodos de estudo

\begin{tabular}{lll}
\hline Etapa & \multicolumn{1}{c}{ Materiais } & \multicolumn{1}{c}{ Método de estudo } \\
Etapa 1 & Seminário da Pesquisa & $\begin{array}{l}\text { Início da pesquisa no primeiro dia de aula das turmas } \\
\text { do segundo e quarto períodos. }\end{array}$ \\
\hline Etapa 2 & Formulário de Competências Coletivas & $\begin{array}{l}\text { Segundo dia de aula, início das 12 observações no } \\
\text { Laboratório de Alimentos para preenchimento dos } \\
\text { formulários da pesquisa. }\end{array}$ \\
\hline \multirow{2}{*}{ Etapa 3} & $\begin{array}{l}\text { Sormulário de Notas Acadêmicas } \\
\text { the Social Science, versão 18.0 }\end{array}$ & $\begin{array}{l}\text { Testes estatísticos: médias dos escores dos } \\
\text { indicadores de CCs e DCs para cálculo do coeficiente } \\
\text { de correlação de Pearson. }\end{array}$
\end{tabular}

Fonte: Elaborado pelos autores.

\section{Instrumentos utilizados na etapa de coleta de dados}

Para obtenção dos dados, elaborou-se o Formulário de Competências Coletivas, empregado na coleta de dados quali-quantitativos da variável Competências Coletivas. Quantitativamente, o instrumento é composto por dez indicadores definidos a partir da revisão teórica dos elementos das CCs: interações afetivas; aprendizagem coletiva (LE BOTERF, 2003); sentido coletivo, base de conhecimento comum; senso de interdependência de tarefas (BOREHAM, 2004); linguagem compartilhada; cooperação compartilhada; memória coletiva; engajamento subjetivo; capital humano - competências individuais (RETOUR; KROHMER, 2011). Os dez indicadores estão escalonados de 1 a 5 , em uma escala do tipo Likert e avaliados conforme os seguintes critérios: (1) Não está presente; (2) Pouco presente; (3) Razoavelmente presente; (4) Bastante presente; (5) Fortemente presente.

Qualitativamente, o formulário apresenta quatro indicadores estabelecidos com base na literatura cientifica de equipes (PARKER, 1994; KATZENBACH; SMITH, 1994, 2001; CASADO, 2002) e de Competências Coletivas (LE BOTERF, 2003):

(a) Indicador "Liderança": baseado na literatura de CCs (LE BOTERF, 2003), indica que a CC não ocorre de forma espontânea, mas requer um gerenciamento adequado da equipe, com saberes e competências de integração entre os membros. Na literatura científica de equipes (KATZENBACH; SMITH, 1994), o gerenciamento refere-se à presença de uma liderança que direciona a equipe à obtenção de resultados superiores; um líder formal cuja coordenação favorece à emergência da CC na equipe. Critério de avaliação: (1) presença de liderança; (2) presença fraca de liderança; (3) presença de dois líderes; (4) ausência de liderança.

(b) Indicador "Perfil dos Integrantes": quatro perfis de integrantes de equipe que definem como serão executadas as tarefas em equipe (PARKER, 1994). Critério de avaliação: (1) Contribuinte - dedica-se à tarefa e fornece boas informações técnicas à equipe; (2) Colaborador - mantém a equipe em direção às metas, com 
atenção voltada para que as metas sejam atingidas; (3) Comunicador - trata as pessoas de modo positivo e as orienta nos processos de trabalho; (4) Desafiador - incentiva a equipe a assumir riscos bem calculados.

(c) Indicador "Metas": na literatura de equipe, as metas são definidas, tanto no individual quanto no coletivo, pelo líder designado. Os membros desenvolvem um senso de compreensão e comprometimento mútuos, as metas coletivas são de responsabilidade dos integrantes e superam o valor das metas individuais (KATZENBACH; SMITH, 2001). Critério de avaliação: (1) Metas diferenciadas em gastronomia; (2) Às vezes, metas diferenciadas em gastronomia; (3) Somente metas de finalização das receitas de gastronomia.

(d) Indicador "Ritmo de Trabalho": ritmo em que a equipe desenvolve as tarefas, velocidade da comunicação, agilidade nas ações e tomada de decisões (CASADO, 2002). Critério de avaliação: (1) Ritmo dinâmico, equipe bastante comunicativa, tomada de decisões rápidas e criativas; (2) Ritmo produtivo, equipe comunicativa, tomada de decisões produtivas. (3) Ritmo lento, pouca comunicação e fraca tomada de decisão.

Para a variável de Desempenho Coletivo foi criado um Formulário de Notas Acadêmicas, formado por 12 temas de gastronomia, desenvolvidos nas aulas do LA. Ao final das observações da pesquisadora foram obtidas doze notas acadêmicas por turma e equipes. Notas acadêmicas atribuídas pelo docente aos pratos gastronômicos produzidos pelas equipes na aula prática, segundo o critério: Finalização de Tarefas. Um parâmetro estabelecido pelo próprio curso de gastronomia e empregado na avaliação das equipes do segundo e quarto períodos, sem diferenciação acadêmica das turmas. As notas acadêmicas poderiam variar de 0 a 10 , com intervalos de 0,5.

\section{ANÁLISE DOS DADOS E DISCUSSÃO DOS RESULTADOS}

$\mathrm{Na}$ abordagem quantitativa, para analisar a correlação entre competências coletivas e desempenho coletivo, foram calculadas médias de CCs e DCs para o cálculo do coeficiente de correlação de Pearson. Os resultados comprovaram a correlação positiva e significativa entre CCs e DCs apenas nas equipes de gastronomia do quarto período.

$\mathrm{Na}$ turma do quarto período, o coeficiente de correlação de Pearson entre CCs e DCs foi 0,731 e significância com $T$ de Student de 0,016 (significante ao nível de $5 \%$ ). 0 resultado se justifica por serem equipes formadas por integrantes que estão no último período do curso, trabalham juntos há mais que um ano e meio, diferenciaram-se pela presença de liderança e indicadores de CCs e já desenvolveram as CCs necessárias ao trabalho em equipe e metas diferenciadas em gastronomia.

Na turma do segundo período, o coeficiente de correlação de Pearson foi 0,199 e significância com $T$ de Student de 0,557 (não significante). Ocorre ausência de correlação significativa entre as variáveis CCs e DCs para essa turma. Este resultado é explicado por serem equipes formadas por integrantes bastante jovens e que estão iniciando o segundo período do curso - uma fase de formação acadêmica e profissional que representa, para muitos integrantes, a primeira vez que desenvolvem um trabalho em equipe. Tecnicamente, um período acadêmico no qual ocorre o aprendizado das receitas gastronômicas e maior vivência em gastronomia, isto é, o desenvolvimento de competências técnicas individuais, antes do desenvolvimento das CCs.

Os resultados demonstram que o desempenho coletivo no segundo período não pode ser atribuído à formação de Competências Coletivas, pois como definem Retour e Krohmer (2011), os atributos referencial comum, linguagem compartilhada, memória coletiva e engajamento subjetivo, como fatores de criação e desenvolvimento de CCs, ainda são emergentes nestas equipes e não impactam no desempenho das mesmas diretamente.

$\mathrm{Na}$ abordagem quantitativa de CCs, para identificar a emergência de competências coletivas durante as tarefas em equipe, foram analisadas as médias dos indicadores quantitativos e os indicadores qualitativos de CCs ou características das equipes. Identificou-se que todas as equipes do segundo e quarto períodos apresentaram formação de CCs durante os trabalhos coletivos no LA.

Nas equipes do quarto período, as médias das pontuações de CCs variaram de 2,48 a 4,28 (em escala de 1 a 5). Houve ausência da pontuação 1 (Não está presente). Comprovou-se que todas as equipes têm formação de CCs durante a execução das tarefas. As melhores equipes apresentaram bastante ou razoável presença de formação de CCs, várias evidências de senso coletivo, senso de interdependência de tarefas, base de conhecimento comum, linguagem compartilhada, cooperação compartilhada, engajamento subjetivo e 
interações afetivas. A aprendizagem coletiva não foi evidenciada em todas estas equipes. Memória coletiva e capital humano apareceram de forma razoável (nem muito nem pouco evidente).

Nas equipes do segundo período, as médias das pontuações de CCs variaram de 2,23 a 3,75 (em escala de 1 a 5), com razoável ou pouca presença de CCs. A maioria das equipes tem ausência da pontuação 1 (Não está presente). Comprovou-se que todas as equipes têm formação de CCs durante a execução das tarefas. As melhores equipes apresentaram razoável presença de formação de CCs e evidências de senso coletivo para o trabalho em equipe.

As equipes criaram de modo razoável uma base de conhecimento comum, baseada em bastante senso de interdependência de tarefas, linguagem compartilhada e cooperação. Os integrantes demonstraram engajamento subjetivo nas atividades em equipe e estabeleceram relações afetivas razoáveis. As melhores equipes do segundo período apresentaram desempenhos semelhantes às melhores equipes do quarto período.

$\mathrm{Na}$ abordagem quantitativa, para comparar o desempenho coletivo com as competências coletivas entre as equipes, foram analisadas as principais características de presença de CCs e os respectivos DCs das equipes. Nas equipes do quarto período, as médias das CCs variaram de 2,48 a 4,28, enquanto os DCs variaram de 9,19 a 9,92 (Tabela 1).

Tabela 1 - Relação entre competências coletivas e desempenho coletivo do quarto período

\begin{tabular}{cccc}
\hline Equipe & $\begin{array}{c}\text { Sequência } \\
\text { Notas }\end{array}$ & CCs & DCs \\
\hline B10 & $1^{\text {a nota }}$ & 4,28 & 9,92 \\
\hline B7 & $2^{\text {a nota }}$ & 3,98 & 9,92 \\
\hline B4 & $3^{\text {a nota }}$ & 3,40 & 9,52 \\
\hline B2 & $4^{\text {a nota }}$ & 4,03 & 9,44 \\
\hline B5 & $5^{\text {a nota }}$ & 2,79 & 9,37 \\
\hline B9 & $6^{a}$ nota & 3,43 & 9,35 \\
\hline B1 & $7^{a}$ nota & 3,00 & 9,32 \\
\hline B8 & $8^{a}$ nota & 3,85 & 9,30 \\
\hline B6 & $9^{a}$ nota & 2,98 & 9,21 \\
\hline B3 & $10^{a}$ nota & 2,48 & 9,19
\end{tabular}

Fonte: Elaborada pelos autores.

Os melhores desempenhos foram das equipes B10, B7, B4 e B2. Exceto pela equipe B4, as outras três também foram as que tiveram mais evidências de competências coletivas.

Nas equipes do segundo período, as médias de CCs variaram de 2,23 a 3,75 e os DCs variaram de 9,17 a 9,81 (Tabela 2). Ao contrário do que aconteceu no quarto período, as equipes que revelaram mais evidências de competências coletivas (B11, B6, B8 e B2) não foram as que tiveram maiores notas, o que já havia sido comprovado, pela baixa correlação entre as varíaveis CCs e DCs.

A primeira e segunda equipes em notas (DCs) referem-se àquelas que realizavam metas de finalização de receitas; diferente das melhores equipes (CCs), que atingiam metas diferenciadas em gastronomia. 
Tabela 2 - Relação entre competências coletivas e desempenho coletivo do segundo período

\begin{tabular}{cc|c|c}
\hline Equipe & $\begin{array}{c}\text { Sequência } \\
\text { Notas }\end{array}$ & $\begin{array}{c}\text { Formulário } \\
\text { CCs }\end{array}$ & $\begin{array}{c}\text { Formulário } \\
\text { DCs }\end{array}$ \\
\hline B10 & $1^{\text {a nota }}$ & 2,57 & 9,81 \\
\hline B9 & $2^{\text {a nota }}$ & 2,98 & 9,69 \\
\hline B11 & $3^{a}$ nota & $\mathbf{3 , 7 5}$ & 9,67 \\
\hline B4 & $4^{a}$ nota & 3,14 & 9,63 \\
\hline B6 & $5^{a}$ nota & 3,31 & 9,58 \\
\hline B8 & $6^{a}$ nota & 3,58 & 9,52 \\
\hline B1 & $7^{a}$ nota & 2,97 & 9,50 \\
\hline B5 & $8^{a}$ nota & 3,19 & 9,38 \\
\hline B7 & $9^{a}$ nota & 3,04 & 9,35 \\
\hline B2 & $1^{a}$ nota & 3,33 & 9,21 \\
\hline B3 & $11^{a}$ nota & $\mathbf{2 , 2 3}$ & 9,17 \\
\hline
\end{tabular}

Fonte: Elaborada pelos autores.

Para a abordagem qualitativa de CCs, a seguir são apresentadas as características das equipes do quarto período nos indicadores de CCs, que influenciaram positivamente os DCs.

(1) Indicador "Perfil dos Integrantes": as melhores equipes são formadas pelos quatro perfis de integrantes para o trabalho coletivo. Os membros contribuintes executam as tarefas, os colaboradores ajudam no alcance das metas. O perfil comunicador do líder facilita na execução das tarefas e por ter, também, o perfil de desafiador, incentiva a equipe a assumir riscos e a desenvolver ações na direção das metas diferenciadas de gastronomia.

(2) Indicador "Liderança": as equipes possuem presença de liderança, que realiza o gerenciamento de membros, distribui as tarefas, promove a participação e a coesão dos integrantes, e mobiliza a equipe no alcance das metas.

(3) Indicador qualitativo de CCs "Metas": as equipes executam as tarefas visando às metas diferenciadas em gastronomia.

(4) Indicador qualitativo de CCs "Ritmo de Trabalho": as equipes desenvolvem as tarefas em ritmo dinâmico, em que a comunicação é bastante utilizada para facilitar a distribuição e a execução das tarefas e proporcionar tomadas de decisões rápidas e criativas.

As observações "em campo" apontam que estas equipes se movimentam bastante na bancada; as posições dos integrantes na área de trabalho são mais flexíveis; as informações circulam com facilidade entre os integrantes porque a comunicação é intensa; os problemas relativos às receitas são discutidos e solucionados pela equipe de forma rápida e criativa.

Nos indicadores qualitativos de CCs, as equipes do segundo período apresentaram resultados similares às equipes do quarto período. As melhores equipes também possuem um líder comunicador e desafiador, o qual orienta integrantes contribuintes e colaboradores nas tarefas e mobiliza as equipes na busca de metas diferenciadas de gastronomia por meio de um ritmo de trabalho dinâmico.

A seguir, apresentam-se a síntese dos resultados das equipes do quarto e segundo períodos (Quadro 3) e o estudo comparativo das equipes, que evidenciam as características predominantes nas melhores equipes do estudo.

A Abordagem Quantitativa dos indicadores de CCs e DCs identificou que as melhores equipes desenvolvem bastante ou razoável CCs (médias dos escores das variáveis) e obtêm melhores desempenhos coletivos na execução das receitas gastronômicas, com presença de correlação positiva e significativa, mas apenas nas equipes do quarto período. Na Abordagem Qualitativa, as melhores equipes são também bem 
avaliadas nos indicadores relativos à composição dos integrantes: o líder é comunicativo e desafiador, exerce 0 gerenciamento das tarefas e dos integrantes contribuintes e colaboradores. Existe bastante comunicação no convívio coletivo, ritmo de trabalho dinâmico nas tarefas e tomada de decisões rápida e criativa na direção de metas diferenciadas de gastronomia. Para Retour e Krohmer (2011), estas são evidências que a criação e 0 desenvolvimento das CCs dependem da presença "mínima" (pouca, razoável, bastante CCs nas melhores equipes de gastronomia) de seus atributos constitutivos (indicadores quali-quantitativos de CCs) para exercer influência positiva sobre os DCs. Do contrário, formam-se grupos de trabalho (CASADO, 2002) em que alguns apenas conseguem atingir a finalização das receitas gastronômicas propostas pelo docente e outros que nem chegam ao final da tarefa proposta.

Cabe destacar que o papel da liderança mostrou ser um diferencial nas melhores equipes: na definição das tarefas, no gerenciamento dos papéis e das posições que os integrantes assumem na bancada durante a execução das receitas gastronômicas. Foi um fator essencial à emergência das CCs (quarto período: 4,28 a 3,40; segundo período: 3,75 a 3,31) aos consequentes desempenhos coletivos diferenciados (notas acadêmicas: $4^{0}$ período: 9,92 a 9,44; segundo período: 9,67 a 9,21), conforme comprovado pelo estudo.

Quadro 3 - Síntese dos resultados das melhores equipes do quarto e segundo períodos

\begin{tabular}{|c|c|c|c|c|c|c|c|c|}
\hline \multicolumn{9}{|c|}{ Abordagem Quantitativa: Formulários de Competência Coletiva e Desempenho Coletivo } \\
\hline \multirow{9}{*}{ 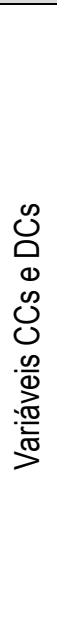 } & \multicolumn{4}{|c|}{ Equipes do Quarto Período } & \multicolumn{4}{|c|}{ Equipes do Segundo período } \\
\hline & Equipe & $\begin{array}{l}\text { Sequência } \\
\text { Notas }\end{array}$ & $\operatorname{CCs}^{1}$ & $\mathrm{DC}^{1}$ & Equipe & $\begin{array}{l}\text { Sequência } \\
\text { Notas }\end{array}$ & CCs ${ }^{1}$ & $\mathrm{DCs}^{1}$ \\
\hline & B10 & $1^{\mathrm{a}}$ & 4,28 & 9,92 & B11 & $3^{\mathrm{a}}$ & 3,75 & 9,67 \\
\hline & B7 & $2^{a}$ & 3,98 & 9,92 & B6 & $5^{\mathrm{a}}$ & 3,31 & 9,58 \\
\hline & B4 & $3^{\mathrm{a}}$ & 3,40 & 9,52 & B8 & $6^{\mathrm{a}}$ & 3,58 & 9,52 \\
\hline & B2 & $4^{\mathrm{a}}$ & 4,03 & 9,44 & B2 & $10^{\mathrm{a}}$ & 3,33 & 9,21 \\
\hline & \multicolumn{2}{|c|}{ Coeficiente de Pearson } & \multicolumn{2}{|c|}{0,731} & \multicolumn{2}{|c|}{ Coeficiente de Pearson } & \multicolumn{2}{|c|}{0,199} \\
\hline & \multicolumn{2}{|c|}{$T$ de Student } & \multicolumn{2}{|c|}{$0,016^{\star *}$} & \multicolumn{2}{|c|}{$T$ de Student } & \multicolumn{2}{|c|}{$0,557^{* *}$} \\
\hline & \multicolumn{4}{|c|}{ Correlação significativa } & \multicolumn{4}{|c|}{ Ausência de correlação significativa } \\
\hline \multicolumn{9}{|c|}{ Abordagem Qualitativa: Formulário de Competência Coletiva² } \\
\hline \multirow{5}{*}{$\frac{\mathscr{J}}{\mathcal{U}}$} & \multicolumn{4}{|c|}{ Melhores equipes do Quarto Período } & \multicolumn{4}{|c|}{ Melhores equipes do Segundo Período } \\
\hline & \multicolumn{2}{|c|}{ Perfil dos Integrantes } & \multicolumn{2}{|c|}{$\begin{array}{l}\frac{\text { Integrantes }}{\text { colaboradores. }} \\
\frac{\text { Líder contribuintes, }}{\text { desafiador }}\end{array}$} & \multicolumn{2}{|c|}{ Perfil dos Integrantes } & \multicolumn{2}{|c|}{$\begin{array}{l}\text { Integrantes contribuintes e } \\
\text { colaboradores. } \\
\text { Líder comunicador e } \\
\text { desafiador }\end{array}$} \\
\hline & \multicolumn{2}{|c|}{ Liderança } & \multicolumn{2}{|c|}{ Presença } & \multicolumn{2}{|c|}{ Liderança } & \multicolumn{2}{|l|}{ Presença } \\
\hline & \multicolumn{2}{|l|}{ Metas } & \multicolumn{2}{|c|}{$\begin{array}{l}\text { Metas diferenciadas de } \\
\text { gastronomia. }\end{array}$} & \multicolumn{2}{|l|}{ Metas } & \multicolumn{2}{|c|}{$\begin{array}{l}\text { Metas diferenciadas de } \\
\text { gastronomia. }\end{array}$} \\
\hline & \multicolumn{2}{|c|}{ Ritmo de Trabalho } & \multicolumn{2}{|c|}{$\begin{array}{l}\text { Ritmo dinâmico, bastante } \\
\text { comunicação, tomada de } \\
\text { decisões rápidas e } \\
\text { criativas }\end{array}$} & \multicolumn{2}{|l|}{ Ritmo } & \multicolumn{2}{|c|}{$\begin{array}{l}\text { Ritmo dinâmico, bastante } \\
\text { comunicação, tomada de } \\
\text { decisões rápidas e } \\
\text { criativas }\end{array}$} \\
\hline
\end{tabular}

Fonte: Elaborado pelos autores.

**: significante ao nível de $5 \%(p<0,05)$

Nota 1: médias dos escores dos indicadores de competência coletiva e desempenho coletivo, escala de 1 a 5.

Nota 2: O formulário de competência coletiva apresenta as características qualitativas identificadas nas equipes com maior presença de competências coletivas (CCs), independentemente das notas de Desempenho Coletivo que obtiveram. 
A Figura 1 apresenta os principais resultados encontrados: o efeito da presença de algumas variáveis qualitativas como preditoras dos indicadores de Competências Coletivas e o impacto moderado pelo período do curso (quarto $x$ segundo) para os resultados de Desempenho Coletivo. $O$ período do curso reflete o tempo em que as equipes trabalham juntas, sendo os do quarto período já com experiência no trabalho em equipes e mais tempo de conhecimento entre seus membros.

Figura 1 - Síntese dos resultados encontrados na pesquisa

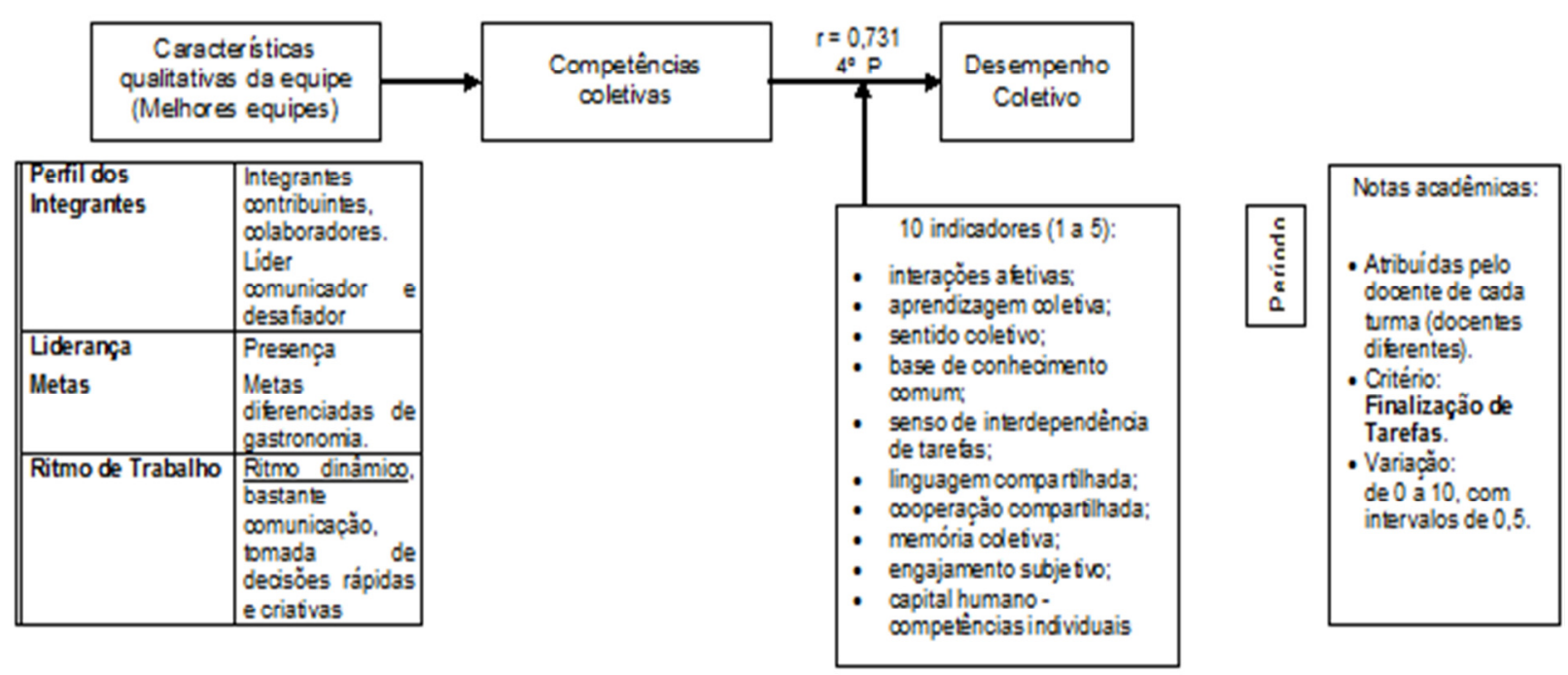

\section{CONSIDERAÇÕES FINAIS}

Esse artigo apresentou um estudo quali-quantitativo em equipes de gastronomia para análise da influência das competências coletivas (CCs) sobre o desempenho coletivo (DC), além de identificar a formação de CCs durante a execução das tarefas em equipe e comparar o desenvolvimento das CCs com o DC.

A Abordagem Quantitativa do estudo comprova que as CCs influenciam positivamente os DCs, pela análise nas equipes do quarto período, que indica correlação significativa $(r=0,731)$ entre as variáveis CCs e DCs. Nas equipes do segundo período, o fato da correlação não ser significativa $(r=0,199)$ pode ter ocorrido por serem equipes jovens, inexperientes no trabalho coletivo, com foco exclusivo na finalização de receitas gastronômicas. Tecnicamente, no segundo período predomina 0 aprendizado e maior vivência em gastronomia, mas não em equipes.

O estudo quantitativo comprova o objetivo específico de que todas as equipes da pesquisa têm formação de CCs durante a execução das tarefas: quarto período com bastante, razoável ou pouca presença de formação de CCs; segundo período, pouca ou razoável presença de formação de CCs.

As melhores equipes do quarto período apresentam bastante ou razoável presença de formação de CCs. Usam bastante o senso coletivo e o senso de interdependência de tarefas para atingir metas diferenciadas de gastronomia e criação de uma base de conhecimento comum bastante presente entre seus integrantes. A linguagem e a cooperação bastante compartilhadas facilitam a aprendizagem e a formação de uma memória coletiva razoável. Os integrantes demonstram bastante engajamento subjetivo nas tarefas coletivas, com interações afetivas bastante intensas entre seus membros. Nas melhores equipes do segundo período, a formação das CCs é razoável. Há presença de senso coletivo para a criação de uma razoável base de conhecimento comum em virtude de terem bastante senso de interdependência de tarefas, linguagem compartilhada e cooperação. $O$ engajamento subjetivo e as relações afetivas são razoáveis e, de modo geral, essas equipes tiveram resultados semelhantes às equipes do quarto período.

A Abordagem Qualitativa evidenciou que as melhores equipes (com maiores escores de CCs independentemente das notas obtidas em DC) têm características comuns de atuação das equipes. $O$ líder formal tem perfil comunicador, é habilidoso no gerenciamento dos membros e tarefas e seu perfil desafiador 
mobiliza a equipe na direção de metas diferenciadas em gastronomia (PARKER, 1994). Estas equipes são compostas por integrantes contribuintes voltados à execução das tarefas e dos colaboradores que ajudam para que a meta seja atingida. Desenvolvem ritmo de trabalho dinâmico e tomada de decisões de forma rápida e criativa (CASADO, 2002) graças a uma comunicação bastante presente entre os membros.

Pelo exposto, os resultados de CCs e DCs respondem à questão investigativa desse artigo: bastante ou razoável presença de CCs influencia positivamente em melhores DCs, comprovada pelas notas acadêmicas altas. E esta correlação positiva decorre de uma presença de certas características presentes no trabalho das equipes.

As observações de campo evidenciaram, nas melhores equipes, a presença de sentido coletivo entre seus membros (BOREHAM, 2004). Esta mente coletiva permitia, no início de cada aula, uma reflexão intencional sobre as receitas, para decidir qual a condução que a equipe adotaria para realizá-las (WEICK, 1993; WEICK; ROBERTS, 1993) Segundo Frohm (2002), a equipe interage buscando uma lógica entre seus integrantes e as tarefas e, dessa forma, consegue estabelecer "o que fazer" e "como executar" as receitas da aula. Os integrantes assumem atitudes de cooperação e de ajuda mútuas, compartilham suas competências individuais e se sentem responsáveis pelo trabalho coletivo da equipe. A coesão afetiva na interação coletiva dá suporte à busca de desempenhos coletivos diferenciados em gastronomia, no tempo e no espaço da aula prática em curso (LE BOTERF, 2003). São equipes com maior consciência e responsabilidade sobre as tarefas (BOREHAM, 2004) e, por isso, o líder consegue fazer emergir as CCs nos integrantes (RETOUR; KROHMER, 2011) e nas entregas individuais do capital humano da equipe, (DUTRA, 2004), comprovadas neste estudo, pelas observações e pelos apontamentos dos indicadores quali-quantitativos de CCs e características dos trabalhos das equipes.

No contexto investigado, o trabalho em equipe se desenvolve em estruturas de trabalho mais flexíveis, menos hierarquizadas, com maior envolvimento e colaboração entre seus integrantes (BOREHAM, 2004). Nas bancadas, os membros são bastante participativos e compromissados com o ato de cozinhar (executam as receitas gastronômicas); valorizam o convívio coletivo e as metas coletivas; e o engajamento subjetivo é estimulado por relações afetivas razoáveis, que, segundo Le Boterf (2003), influenciam fortemente para que seus membros se sintam à vontade e tenham prazer pelo convívio coletivo, investindo no surgimento das CCs na equipe da qual fazem parte. Características que podem ser encontradas em outros contextos organizacionais, além do ramo da gastronomia.

O papel da liderança mostrou ser um diferencial nas melhores equipes e comprovou ser uma das condições para a emergência das CCs: implementar um gerenciamento apropriado a uma situação específica de trabalho (LE BOTERF, 2003). Nas melhores equipes de gastronomia ficou evidente que a presença formal de uma liderança bem estabelecida promoveu a interação e a aderência coletiva dos membros à equipe. Lembrando que as melhores equipes estão juntas há mais que um ano e meio. Ou seja, a liderança é determinante na formação de equipes de trabalho com melhores CCs e DCs.

Como contribuições, a pesquisa empírica evidenciou que os elementos de CCs propostos pelos principais autores da literatura científica (LE BOTERF, 2003; BOREHAM, 2004; RETOUR; KROHMER, 2011) poderão ser utilizados em outros contextos organizacionais como indicadores de CCs. Ainda que os objetivos tenham sido alcançados, admite-se a limitação da pesquisa de ter sido realizada em apenas uma universidade e em 21 equipes, amostragem pequena para testes de correlação. Entretanto, apesar dos resultados não poderem ser generalizados, o método da pesquisa e os conceitos teóricos poderão ser testados em outras realidades, a fim de que resultados numericamente mais significativos legitimem a influência positiva da CC sobre o DC.

$\mathrm{Na}$ ocorrência de novas pesquisas, na variável de desempenho coletivo, sugere-se 0 uso de notas acadêmicas mais detalhadas por itens ou por etapas, e diferenciação acadêmica por período do curso. No estudo, as notas acadêmicas que serviram de base de correlação entre as variáveis CCs e DCs apresentaram pequenas variações, em função do critério de avaliação: finalização de receitas de gastronomia. Um critério estabelecido pela própria universidade e que não foi suficientemente forte para captar a diferenciação das equipes: quarto período, notas: 9,92 a 9,19; segundo período, notas: 9,81 a 9,17. Sugere-se também em estudos futuros fazer uso da "escala de desempenho de equipe" de Barbosa (2009) para análise dos fatores de tarefa e desempenho contextual, um instrumento aqui não utilizado, mas que pode ser utilizado concomitantemente com as notas acadêmicas.

Como agenda futura, o estudo propõe novos testes de correlação entre CCs e DCs, aplicados em outros contextos organizacionais (acadêmicos; empresariais); em especial, no ramo de gastronomia, a fim de 
contribuir para a consolidação da temática em debate. Sugerem-se também outros estudos que contribuam para a melhora dos resultados das equipes acadêmicas e em contextos organizacionais, nos quais as equipes são utilizadas como unidade de desempenho.

Por fim, um estudo longitudinal das equipes do segundo período, quando estiverem no quarto período do curso, para novos testes de correlação, que confirmem ou não a ausência de correlação observada nesta pesquisa, acrescentando a variável "tipo de bancada" e analisando equipes que trabalham em bancadas de formato regular (um integrante ao lado do outro) e em bancadas de formato "ilha" (integrantes frente a frente), ambas utilizadas na cozinha contemporânea. Ainda mais estudos sobre Liderança na gestão de equipes, visto que o gerenciamento apropriado é uma condição para a emergência da CCs. DCs.

\section{REFERÊNCIAS}

ARAUJO, J.B.C.; CANÇADO, V.L. Relações entre confiança e desempenho de equipes. Rio de Janeiro, 2011. In: XXXV Encontro da ANPAD. Anais... ANPAD: Rio de Janeiro, 2011, p.1-17. Disponível em:<http://www.anpad.org.br/admin/pdf/2013_EnANPAD_GPR1914.pdf>. Acesso em: 25 fev. 2015.

BEDANI, M. Efetividade das equipes de trabalho: clima organizacional como variável preditora do desempenho. Rio de Janeiro, 2007. In: XXXI Encontro da ANPAD. Anais... ANPAD: Rio de Janeiro, 2007, p.1-13. Disponível em: <http://www.anpad.org.br/diversos/ trabalhos/EnANPAD/enanpad_2007/EOR/2007_EORB756.pdf>. Acesso em: 15 mar. 2015.

BENDERS, J.; VAN HOOTEGEM, G. Teams and their context: moving the team discussion beyond existing dichotomies. Journal of Management Studies, 36, 609-628, 1999.

BITENCOURT, C. C.; KLEIN, M. J. A dinâmica das competências coletivas entre grupos de trabalho: o caso da parada geral de manutenção da UNIB-RS/ Braskem. São Paulo, 2009. In: XXXIII Encontro da ANPAD. Anais... ANPAD: São Paulo, 2009, p.1-16. Disponível em: <http://www.anpad.org.br/admin/pdf/EOR702.pdf>. Acesso em: 23 set. 2014.

BLANCHARD, K; BLANCHARD, M.; CAREW, D.; FINCH, F. [Orgs]. Liderança de Alto Nível: como criar e liderar organizações de alto desempenho. Porto Alegre: Bookman, 2007.

BONOTTO, F.; BITENCOURT, C. C. Os elementos das competências coletivas em grupos de trabalho: a experiência da COPESUL. Salvador, 2006. In: XXX Encontro da ANPAD. Anais... ANPAD: Salvador, 2006, p.114. Disponível em: <http://www.anpad.org.br/ enanpad/2006/dwn/enanpad2006-eorb-1882.pdf>. Acesso em: 15 mar. 2015.

BOREHAM, N. A theory of collective competence: challenging the neo-liberal individualisation of performance at work. British Journal of Educational Studies. ISSN

0007-1005, v.52, n.1. p. 5-17, mar. 2004. Disponível em: < http://onlinelibrary.wiley.com/doi/ 10.1111/j.14678527.2004.00251.x/abstract>. Acesso em: 15 mar. 2015.

CASADO, T. O indivíduo e o grupo: a chave do desenvolvimento. In: PROGEP. As pessoas na organização. São Paulo: Editora Gente, 2002, cap.1, p.235-246.

COLIN,T.; GRASSER, B. Das competências individuais à competência coletiva: contribuições da aprendizagem em um serviço de emergência hospitalar. In: Competências Coletivas: no limiar da estratégia. Retour, D.; Picq, T.; Defelix, C.; Ruas, R. São Paulo: Bookman, 2011.

DUHÁ, A. H. Organizações de equipes efetivas: variáveis, processos e estratégias de investigação. 2007. 98f. 2007. Tese de Doutorado. Tese (Doutorado em Psicologia) -Programa de Pós-Graduação da Faculdade de Psicologia, Pontifícia Universidade Católica do Rio Grande do Sul. Porto Alegre.

FROHM, C. Collective competence in an interdisciplinary project context. Sweden: Linköpings universitet, 2002.

HANSSON, H. Kollektiv kompetens. Lund, Sweden: Studentlitteratur, 2003. In: FROHM, C. Collective competence in an interdisciplinary project context. Sweden: Linköpings universitet, 2003.

IVANCEVICH, J. M. Gestão de recursos humanos. São Paulo: McGraw-Hill, 2008, cap.13, p.425-426. 
KATZENBACH, J. R. Equipes campeãs: desenvolvendo o verdadeiro potencial de equipes e líderes. Rio de Janeiro: Campus, 2001.

KATZENBACH, J. R.; SMITH, D. K. Equipes de alta performance: Disciplina das equipes: conceitos, princípios e técnicas para potencializar o desempenho das equipes. Rio de Janeiro: Campus, 2001.

KATZENBACH, J. R.; SMITH, D. K. A força e o poder das equipes. São Paulo: Makron Books, 1994.

LE BOTERF, G. Desenvolvendo a competência dos profissionais. Porto Alegre: Artmed, 2003.

MACHADO, M. Equipes de trabalho: sua efetividade e seus preditores, 1998. Tese (Mestrado). Universidade de Brasília : Brasília, 1998.

MICHAUX, V. Compétences Collectives et haute performance: apports thóriques et enjeux opérationnels. Revue de Gestion des Resources Humaines, v.58, p. 45-66, out./dez., 2005.

MICHAUX, V. Articular as competências individual, coletiva, organizacional e estratégica: esclarecendo a teoria dos recursos e do capital social. In: RETOUR, D.; PICQ, T.; DEFÉLIX, C.; RUAS, R. Competências Coletivas: no limiar da estratégia. Porto Alegre: Bookman, 2011. cap. 1, p. 1-22.

MOSCOVICI, F. Equipes dão certo: a multiplicação do talento humano. Rio de Janeiro: José Olympio, 2010.

PARKER, G. M. Team Players \& Teamwork: a equipe e seus integrantes. Rio de Janeiro: Campus, 1994.

PUENTE-PALACIOS, K. Equipes de trabalho. In: SIQUEIRA, M. M. M. et al. (Org.). Medidas do comportamento organizacional: ferramentas de diagnóstico e de gestão. Porto Alegre: Artmed, 2008, cap.9, p. 145-160.

PUENTE-PALÁCIOS, K.E.; SOUZA, M.G.S. Satisfação com o trabalho em equipe: qual o papel do autoconceito profissional. São Paulo, 2009. In: XXXIII Encontro da ANPAD. Anais... ANPAD: São Paulo, 2009, p.1-14. Disponível em: <http://www.anpad.org.br/ admin/pdf/GPR2439.pdf>. Acesso em: 25 fev. 2015

PUENTE-PALÁCIOS, K.E.; SEIDL, J.; SILVA, R. A. D. O impacto da percepção das diferenças na satisfação de equipes de trabalho. Rio de Janeiro, 2007. In: XXXI Encontro da ANPAD. Anais... ANPAD: Rio de Janeiro, 2007, p.1-13. Disponível em: < http://www.anpad.org.br/admin/pdf/GPR-A2033.pdf>. Acesso em: 25 fev. 2015.

PUENTE-PALÁCIOS, K.E.; BORGES-ANDRADE, J.E. O efeito da interdependência na satisfação de equipes de trabalho: um estudo multinível. RAC-Revista de Administração Contemporânea. v.9, n.3, p.1-22, jul/set, Curitiba, 2005. Disponível em: < http://www.scielo.br/scielo.php?script=sci_arttext\&pid=S141565552005000300004>. Acesso em: 15 mar. 2015.

RETOUR, D.; KROHMER, C. A competência coletiva: uma relação-chave na gestão das competências. In: RETOUR, D.; PICQ, T.; DEFÉLIX, C.; RUAS, R. L. (Orgs.). Competências coletivas: no limiar da estratégia. Porto Alegre: Bookman, 2011, cap.3, p.45-78.

RODRIGUES, A.J. Metodologia científica: completo e essencial para a vida universitária. São Paulo: Avercamp, 2006.

RUAS, R.; ANTONELLO, C.S.; BOFF, L.H. Gestão por competências: uma contribuição à estratégia das organizações. In: RUAS, R.; ANTONELLO, C. S.; BOFF, L. H. Os novos horizontes da Gestão: aprendizagem organizacional e competências. Porto Alegre: Bookman, 2005.

SILVA, F. M. O que sabemos sobre competências coletivas. In: XXXVI Encontro do Anpad. Anais... ANPAD: Rio de Janeiro: 2012, p.1-14. Disponível em: < http://www.anpad.org.br/admin/pdf/2012_GPR2432.pdf>. Acesso em: 15 mar. 2015.

VASQUEZ, A.C.; OLTRAMARI, A.P.; TONON, L.; GARAY, A.B.S. Desempenho e carreira: um panorama da produção acadêmica no período de 2000 a 2010. DESENVOLVE: Revista de Gestão do Unilasalle, v. 2, n. 1, 2013. Disponível em: <http://gvpesquisa.fgv.br/sites/ gvpesquisa.

fgv.br/files/arquivos/andrea_poleto_oltramari_desempenho_e_carreira_ producao_academica_brasileira_em_administracao_no_periodo_de_2000_a_2010.pdf>. Acesso em: 15 mar. 2015.

WEBER, L.; GRISCI, C.L.I. Equipe, grupo... o quê?: Possibilidades relativas ao coletivo no trabalho imaterial. In: XXXIV Encontro da ANPAD. Rio de Janeiro 2010. Anais... ANPAD: 2010, p.1-16. Disponível em: < http://www.anpad.org.br/admin/pdf/gpr1934.pdf>. Acesso em: 25 fev. 2015. 
WEICK, K. E. Sensemaking in organizations. Thousand Oaks, CA: Sage, 1993.

WEICK, K. E.; ROBERTS, K. H. Collective mind in organizations: heedful interrelation on flight decks. Administrative Science Quarterly, v. 38, n. 3, pp. 357-381, 1993.

ZAMPIER, M. A.; TAKAHASHI, A. R. W. Competências e aprendizagem empreendedora em MPE'S educacionais. Revista Pensamento Contemporâneo em Administração, v. 8, n. 3, p. 1-22, 2014. Disponível em:< http://www.uff.br/pae/index.php/pca/article/view/335>. Acesso em: 25 fev. 2015.

ZARIFIAN, P. Objetivo competência: por uma nova lógica. São Paulo: Atlas, 2001. 